\title{
Hydroxyapatite Coatings on a 3D Porous Surface Using Thermal Substrate Method
}

\author{
Kensuke Kuroda $^{1}$, Shinji Nakamoto ${ }^{1, *}$, Ryoichi Ichino ${ }^{1}$, \\ Masazumi Okido ${ }^{1}$ and Robert M. Pilliar ${ }^{2}$ \\ ${ }^{1}$ Department of Materials Science and Engineering, Nagoya University, Furo-cho, Chikusa, Nagoya 464-8603, Japan \\ ${ }^{2}$ Institute of Biomaterials and Biomedical Engineering, University of Toronto, \\ 4 Taddle Creek Road, Toronto, Ontario, Canada M5S $3 G 9$
}

\begin{abstract}
Hydroxyapatite (HAp) coated films were obtained using a thermal substrate method, whereby an aqueous solution at $\mathrm{pH}=7$ or 8 containing $\mathrm{Ca}^{2+}$ and $\mathrm{PO}_{4}{ }^{3-}$ ions was used to deposit a coating on porous-surfaces substrates formed by sintering $44-150 \mu \mathrm{m}$-sized Ti6Al4V powders on a solid commercially pure titanium (cpTi) base. The HAp coating conditions used were: coating time $=\sim 900 \mathrm{~s}$ and substrate temperature equal to 373 or $393 \mathrm{~K}$. Coatings formed in a $\mathrm{pH}=7$ solution at $373 \mathrm{~K}$ for $900 \mathrm{~s}$ and in a pH $=8$ solution at $393 \mathrm{~K}$ for $300 \mathrm{~s}$ showed that all of the surfaces of the Ti6Al4V sintered particles (both front and back faces) and the base cpTi substrate were covered with HAp, and that they maintained their original open-pored geometry. The precipitated HAp appeared to be denser on porous-surfaced samples compared with plain-surfaced cpTi samples. Use of the thermal substrate method with appropriate $\mathrm{pH}$ control, and substrate heating temperature and time was effective for forming HAp coatings on powder-sintered samples with a complex topography.
\end{abstract}

(Received November 19, 2004; Accepted February 3, 2005; Published July 15, 2005)

Keywords: hydroxyapatite, thermal substrate method, bioactive coating, aqueous process, porous-surfaced titanium

\section{Introduction}

Hydroxyapatite $\left(\mathrm{Ca}_{10}\left(\mathrm{PO}_{4}\right)_{6}(\mathrm{OH})_{2}, \mathrm{HAp}\right)$ is of interest for bone-interfacing implant applications, because of its demonstrated osteoconductive properties. ${ }^{1)}$ Hydroxyapatite is considered to be a bioactive material, and it is used in the fabrication of medical and dental implants, usually in the form of a coating on a metallic substrate, because of its poor intrinsic mechanical properties. Such designs are intended to take advantage of the bioactivity of HAp in combination with the strength of the metallic substrate. The combination of plasma-sprayed HAp on a Ti or Ti alloy substrate is currently used in the fabrication of artificial joint replacements ${ }^{1)}$ and endosseous dental implants. ${ }^{2)}$ While other coating methods for HAp and calcium phosphate on metallic substrates have been reported (e.g., magnetron sputtering, ${ }^{3)}$ cathodic electrolysis precipitation, ${ }^{4-8)}$ and sol-gel coating ${ }^{9)}$ ), plasma spraying remains the most commonly used technique. Kokubo et al. have proposed a process that combines immersion in aqueous $\mathrm{NaOH}$ solution and a heat treatment to produce an osteoconductive surface, which was not a HAp coating process. ${ }^{10)}$

The surface geometric design of load-bearing, boneinterfacing implants, such as those used in orthopaedics and dentistry, is an important consideration for achieving reliable, long-term implant fixation. The use of implants prepared with sintered porous surfaces represents one approach that is currently used to achieve good fixation through bone ingrowth into the resulting three-dimensional (3-D) porous structure. In addition to providing good longterm implant fixation, recent studies have demonstrated that such surface designs also encourage more rapid implant osseointegration. ${ }^{11)}$ Therefore, metallic implants with porous surfaces coated with HAp would presumably result in even more rapid bone ingrowth and implant fixation. The

*Graduate Student, Nagoya University formation of HAp coatings on porous surfaces using plasma spraying has been reported. ${ }^{2)}$ However, the line-of-sight nature of plasma spray deposition, and the normally relatively thick coatings achieved can severely occlude the desired pore sizes, thereby limiting the usefulness of this technique. In our study, another approach for forming thin film coatings on porous Ti alloy surfaces formed by sintering Ti6Al4V particles on cpTi substrates was investigated namely using a thermal substrate method in an aqueous solution, as previously proposed. ${ }^{12,13)}$ That is to say, the objective of this study was to confirm whether the thermal substrate method was effective for the HAp coating on the porous surfaces.

\section{Experimental}

\subsection{D porous surfaced samples}

The surface of the experimental test samples was modified by applying a sintered porous Ti6Al4V surface layer, which was formed by methods that have been described previously. ${ }^{14)}$ This involved sintering 44-150 $\mu \mathrm{m}$-sized Ti6Al4V particles at $1523 \mathrm{~K}$ for $3.6 \mathrm{ks}$ in a high-vacuum furnace. The resulting surface region consisted of a porous structure with approximately $35-40$ vol\% porosity. The pores formed a three-dimensional interconnected network within an approximately $200 \mu \mathrm{m}$ thick surface zone. ${ }^{11,14)}$ The surface area of the porous-surfaced samples was estimated to be approximately five to seven times larger than that of a smoothsurfaced sample. ${ }^{14)}$ Smooth-surfaced samples were also prepared with the surface finished by using 600 grid SiC. The porous- and smooth-surfaced samples were both degreased and cleaned using acetone.

\subsection{HAp coating}

Because the coating theory and the experimental apparatus and procedure were almost the same as has been previously reported, ${ }^{12,13)}$ they are only described briefly here. The 
solution used contained $0.3 \mathrm{mmol} \mathrm{dm}{ }^{-3}$ of $\mathrm{Ca}\left(\mathrm{H}_{2} \mathrm{PO}_{4}\right)_{2}$ and $0.7 \mathrm{mmol} \mathrm{dm}^{-3}$ of $\mathrm{CaCl}_{2}$. The $\mathrm{pH}$ value of the solution was adjusted to $\mathrm{pH}=7$ or 8 by the addition of aqueous $\mathrm{NaOH}$ to obtain HAp as a predominant precipitate. ${ }^{13)}$ The poroussurfaced samples attached to the copper electrodes were then immersed into $0.2 \mathrm{dm}^{3}$ of the aqueous solution, and shaken to release any adhered air bubbles on their surface. An alternating current (up to $40 \mathrm{~A}$ ) was passed through the samples via the copper electrodes, which resulted in localized heating of the samples. The temperature of the samples was measured using a calibrated thermocouple, which was in contact with the upper surface of the samples. The temperature was maintained at 373 or $393 \mathrm{~K}$ by controlling the applied current, and the coating process was terminated by switching off the power. These temperatures were selected because it was easy to control the thickness of coating films. Following this treatment, the properties of the samples were studied using thin-film X-ray diffraction (XRD) and scanning electron microscopy (SEM).

\section{Results and Discussion}

A white precipitate was observed on all the samples after the experiments. No apparent difference between the upper face and the lower face of the coated substrates was observed, as the samples were positioned horizontally in the solution during the coating procedure. From the XRD analysis, it was verified that the precipitate was HAp. Figures 1 and 2 show the surfaces and cross-sectional views of the porous- and smooth-surfaced samples after coating using the thermal substrate method at $393 \mathrm{~K}$ in a $\mathrm{pH}=8$ solution, and at $373 \mathrm{~K}$ in a $\mathrm{pH}=7$ solution. The cross-sections were of surfaces taken after the coated specimens had been bent. Heating at
$393 \mathrm{~K}$ for $300 \mathrm{~s}$ in a $\mathrm{pH}=8$ solution and at $373 \mathrm{~K}$ for $900 \mathrm{~s}$ in a $\mathrm{pH}=7$ solution led to HAp precipitation over the entire surface of the Ti6Al4V sintered particles (on both the front and back faces), and also on the base cpTi substrate of the experimental samples. In particular, it was found that HAp precipitate was also detected at the sinter neck regions of adjacent particles (see "A" in Fig. 2), and on the base substrate before bending the samples, while the original open-pored geometry was maintained. However, the smoothsurfaced samples were not fully covered by HAp after the experiments carried out at $373 \mathrm{~K}$ for $900 \mathrm{~s}$ in the $\mathrm{pH}=7$ solution. High magnification photographs (Fig. 3) revealed that uncoated open space was left between the HAp clusters and precipitated HAp crystals grew larger on the smoothsurfaced samples, compared with the porous-surfaced sample. This indicated that the HAp precipitates appeared to be denser on the porous-surfaced samples when compared to the smooth-surfaced samples. The reason for this different response may be as follows; in our experiments, we observed that a few large bubbles were generated on the smoothsurfaced samples compared to the more abundant smaller bubbles that were generated on the porous-surfaced samples. This is to be expected, since the porous surface presents a more uneven surface that would result in higher bubble nucleation rates than would be expected on a plain surface. Therefore, the more frequent release of smaller bubbles from the porous surfaces would promote local stirring of the solution at the sample surface which, in turn, would also result in a more homogeneous precipitation.

In the experiments carried out at $393 \mathrm{~K}$ and at $\mathrm{pH}=8$ for long periods (600 and $900 \mathrm{~s}$ ), an open-pored geometry was not maintained, because excess HAp precipitation occurred on the outer surface of the samples. Below this outer surface

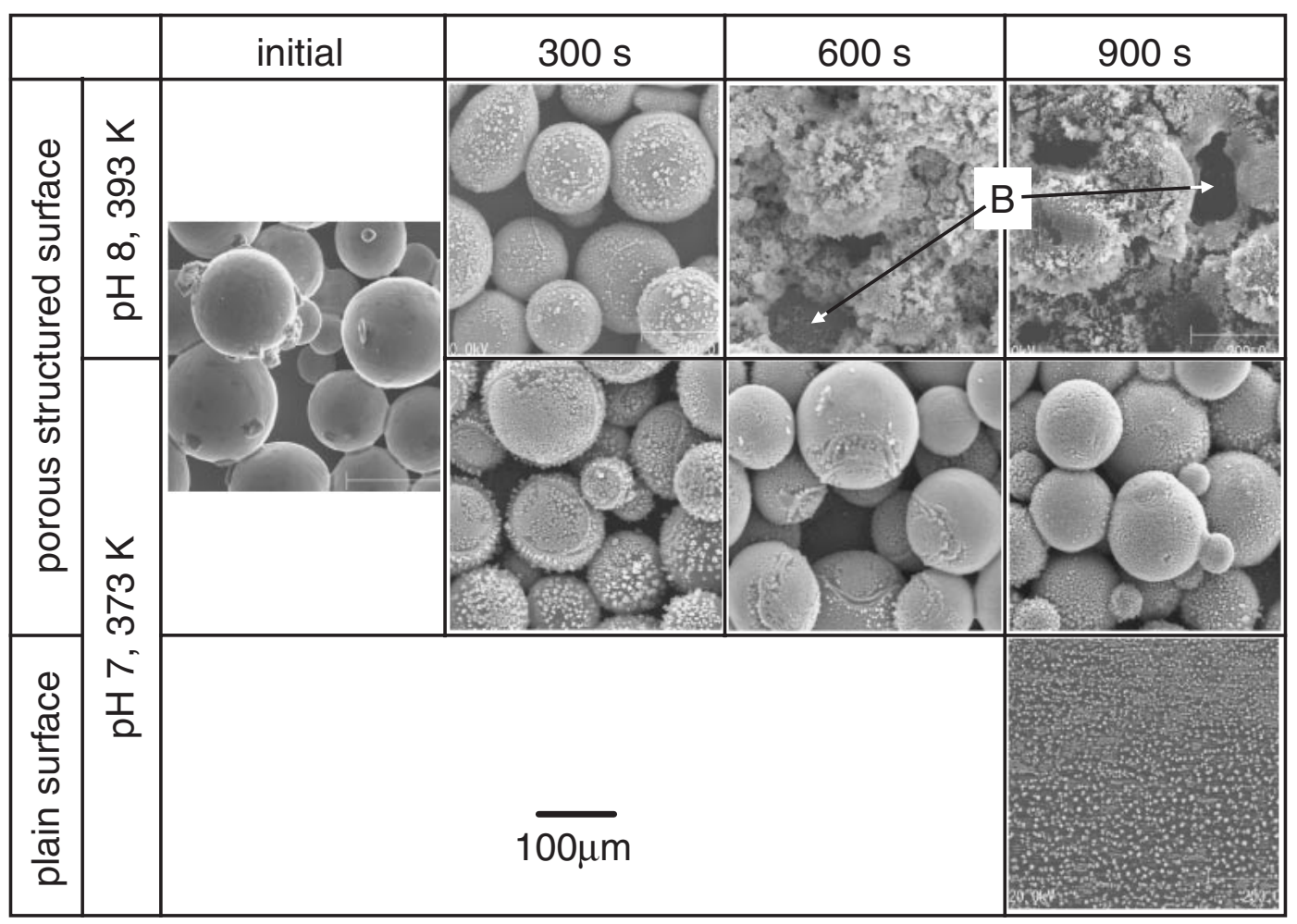

Fig. 1 Surface view of porous- and plain-surfaced samples after coating at $393 \mathrm{~K}$ in a $\mathrm{pH}=8$ solution and at $373 \mathrm{~K}$ in a pH $=7 \mathrm{solution}$. 


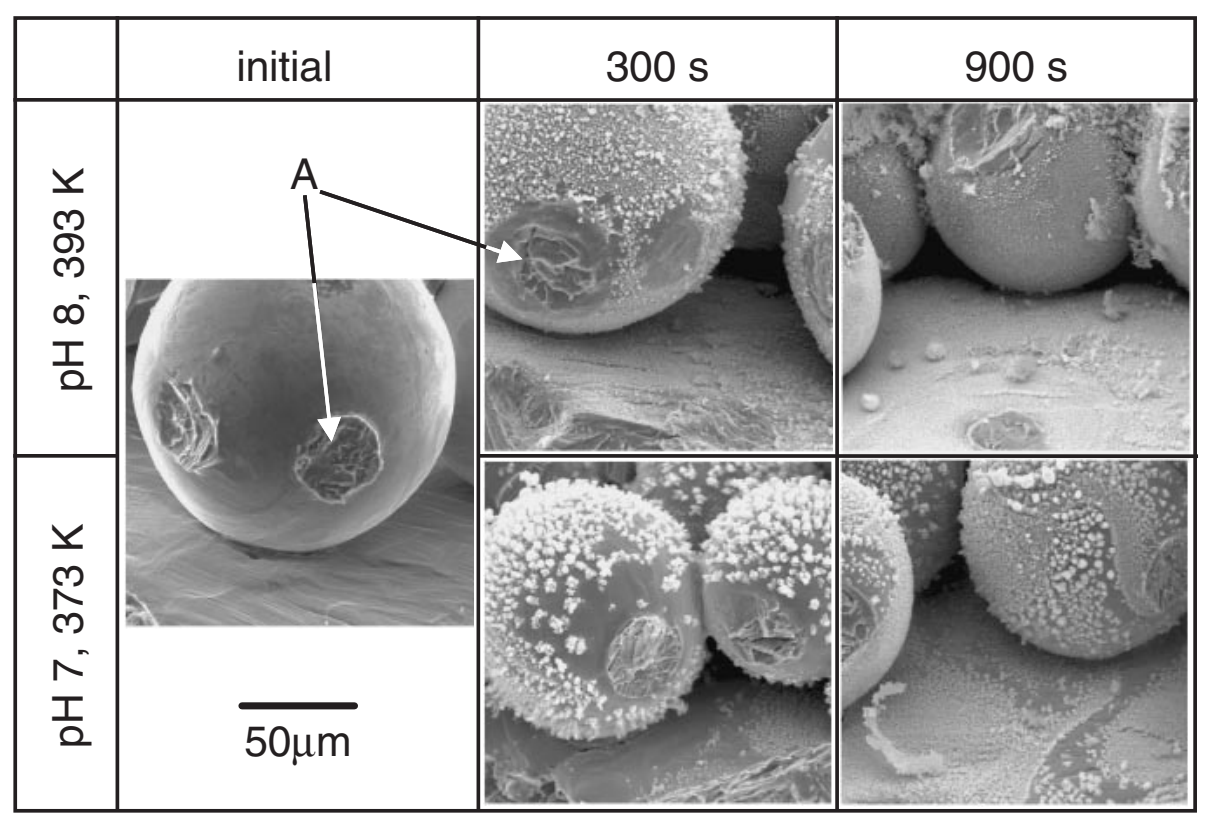

Fig. 2 Cross-sectional views of porous-surfaced samples after coating at $393 \mathrm{~K}$ in a $\mathrm{pH}=8$ solution and at $373 \mathrm{~K}$ in a pH $=7$ solution.
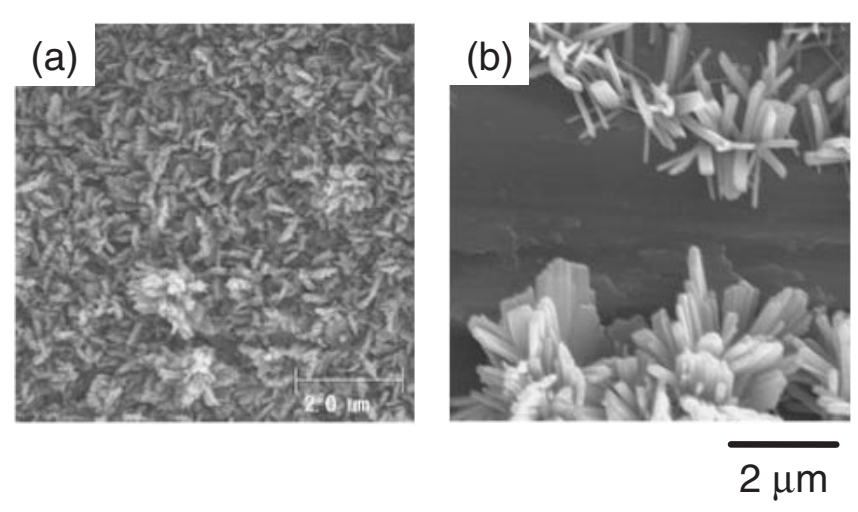

Fig. 3 High magnification surface view of the porous-surfaced sample after coating at $393 \mathrm{~K}$ in a $\mathrm{pH}=8$ solution for $300 \mathrm{~s}$ (a) and of the smoothsurfaced samples after coating at $373 \mathrm{~K}$ in a $\mathrm{pH}=7$ solution (b).

and particularly towards the titanium substrate, the openpored structure was retained presumably as a result of the lower degree of HAp precipitation in these regions. The outer surface, while retaining the porous structure of the sintered Ti6Al4V, also displayed many large openings (see "B" in Fig. 1), that are believed to have resulted from the generation of water vapour bubbles on the inside of the porousstructured samples. It is thought that the precipitation of HAp occurs more easily on the outer surface than on the inner surfaces, because of the stirring effect of the small bubble formation on the solution containing $\mathrm{Ca}^{2+}$ and $\mathrm{PO}_{4}{ }^{3-}$ ions, as described above. Our experimental results indicate the formation of a denser and more even coating on the porous-surfaced samples with appropriate control of $\mathrm{pH}$ of the solution, temperature of the substrate, and heating time.

\section{Conclusion}

Dense HAp coatings can be obtained on Ti6Al4V poroussurfaced samples while maintaining the original open-pored geometry by using the thermal substrate method with appropriate coating conditions namely an aqueous solution with $\mathrm{pH}=7$, substrate held at $373 \mathrm{~K}$ for $900 \mathrm{~s}$, or $\mathrm{pH}=8$ and the substrate held at $393 \mathrm{~K}$ for $300 \mathrm{~s}$. HAp precipitates appear to be denser on the porous-surfaced samples compared with plain-surfaced samples.

\section{Acknowledgements}

This work was partially supported by a Grant-in-Aid for Young Scientist (B) (No. 15760520) from the Japan Society for the Promotion of Science (JSPS). The sintered poroussurfaced samples were kindly provided by the Innova Corporation (Toronto, Canada).

\section{REFERENCES}

1) L. L. Hench and J. Wilson: An Introduction to Bioceramics, (World Scientific Publishing, Singapore, 1993).

2) R. M. Pilliar, D. A. Deporter, P. A. Watson, M. Pharoah, M. Chipman, N. Valiquette, S. Carter and K. DeGroot: J. Dent. Res. 70 (1991) 13381345.

3) K. Yamashita, T. Yagi and T. Umegaki: J. Am. Ceram. Soc. 79 (1996) 3133-3316.

4) H. Monma: J. Mater. Sci. 29 (1994) 949-953.

5) S. Ban and S. Maruno: J. Biomed. Mater. Res. 42 (1998) 387-395.

6) Y. Han, K. Xu and J. Lu: J. Mater. Sci. Med. 10 (1999) 243-248.

7) M. Shirkhanzadeh: J. Mater. Sci. Lett. 10 (1991) 1415-1417.

8) M. Shirkhanzadeh: J. Mater. Sci.: Mater. Med. 6 (1995) 90-93.

9) W. Weng: J. Am. Ceram. Soc. 82 (1999) 27-32.

10) T. Kokubo, F. Miyaji, H. Kim and T. Nakamura: J. Am. Ceram. Soc. 79 (1996) 1127-1129.

11) C. A. Simmons, N. Valiquette and R. M. Pilliar: J. Biomed. Mater. Res. 47 (1999) 127-138.

12) K. Kuroda, R. Ichino, M. Okido and O. Takai: J. Biomed. Mater. Res. 59 (2002) 390-397.

13) K. Kuroda, R. Ichino, M. Okido and O. Takai: J. Biomed. Mater. Res. 61 (2002) 354-359.

14) R. M. Pilliar: Inter. J. Powder Metall. 34 (1998) 33-45. 